\title{
Effects of Fuel Prices on Air Transportation Performance at New York and San Francisco Airports
}

\author{
John Ferguson; Karla Hoffman; Lance Sherry; Abdul Qadar Kara \\ Center for Air Transportation Systems Research, George Mason University, Fairfax, VA
}

\begin{abstract}
Industry strategists, government regulators, and the media have focused on addressing concerns over the performance of the air transportation system with respect to delays. One of the strategies proposed has been to limit the scheduled operations at an airport to a priori feasible capacity limits. This approach has been criticized on the basis that it would reduce the number of markets served and increase airfares.
\end{abstract}

This paper describes a comparison of the behavior of the of the air transportation system (e.g. markets, economics, and performance) during the recent run-up in fuel prices at slot-controlled New York airports and non-slot controlled San Francisco airports. The results indicate that slot controlled airports yielded improved performance (e.g. less delayed and cancelled flights) through reductions in frequency and de-peaking schedules. There was no significant change in markets service. However, there is a marked decrease in the number of markets served by two or more airlines.

On the other hand, the non-slot controlled airports in the San Francisco region showed an increase in flight delays and cancellations during the same period. The number of market served and airfares did not change. These results provide some justification for slot-controls at airports that need to manage network congestion. Even in the presence of fluctuations in passenger demand and economic shocks, passengers saw an improvement in service (i.e. a lessening of delays and cancellation) without any significant loss in markets served or frequency to those markets. The only significant reduction in frequency was to the Washington DC, Chicago and Boston markets where there was decrease in frequency and an upguaging of aircraft to accommodate the passenger demand.
Keywords: Economic analysis, Performance metrics, Longitudinal analysis, airport delays, market analysis, metroplex.

\section{INTRODUCTION}

In 2007, passengers flying domestic routes in the U.S. experienced 281.4 million hours of passenger trip delays ${ }^{1}$. The Senate Joint Economic Committee estimates that these delays represent a $\$ 40 \mathrm{~B}$ cost to the US Economy. ${ }^{23}$

Industry strategists, government regulators, and the media have focused on addressing concerns over the performance of the air transportation system with respect to delays. One of the strategies proposed has been to limit the scheduled operations at an airport to a priori feasible capacity limits. This approach has been criticized on the basis that it would reduce the number of markets served and increase airfares.

This report provides a longitudinal study of the New York (Newark Liberty, New York John F. Kennedy, and LaGuardia) and San Francisco Metroplex airports (San Francisco International, San Jose, and Oakland). The New York airports are being examined since they are responsible for $12 \%$ of total national delays. ${ }^{4}$ Additionally the New York Metroplex is currently the only metroplex in the national network where all three major airports are slot controlled and where there is no ability to expand in the near future. At LaGuardia, the average delay is over 70 minutes most afternoons. ${ }^{5}$ Within the next ten years annual air travel is expected to reach 1.1 billion air travelers a year in the United States. ${ }^{678}$ This study expands on that effort and compares the performance at the New York airports to the performance at the San Francisco airports, and extends the time period covered to include 2008, when fuel costs rose significantly during the summer months. 
This paper describes a comparison of the behavior of the of the air transportation system (e.g. markets, economics, and performance) during the recent run-up in fuel prices at slot-controlled New York airports and non-slot controlled San Francisco airports. The results indicate that slot controlled airports yielded improved performance (e.g. less delayed and cancelled flights) through reductions in frequency and de-peaking schedules, see table 1. There was no significant change in markets service. However, there is a marked decrease in the number of markets served by two or more airlines.

On the other hand, the non-slot controlled airports in the San Francisco region showed an increase in flight delays and cancellations during the same period. The number of market served and airfares did not change. These results provide some justification for slot-controls at airports that need to manage network congestion. Even in the presence of fluctuations in passenger demand and economic shocks, passengers saw an improvement in service (i.e. a lessening of delays and cancellation) without any significant loss in markets served or frequency to those markets. The only significant reduction in frequency was to the Washington DC, Chicago and Boston markets where there was decrease in frequency and an upguaging of aircraft to accommodate the passenger demand.

\begin{tabular}{|c|c|c|c|c|}
\hline \multicolumn{2}{|c|}{ Design } & \multicolumn{3}{|c|}{ Summary of Analysis } \\
\hline Fuel Prices & $\begin{array}{c}\text { Slot } \\
\text { Controls }\end{array}$ & Market & Economic & $\begin{array}{c}\text { Flight } \\
\text { Performance }\end{array}$ \\
\hline \multirow{2}{*}{$\begin{array}{l}+57 \% \\
2005-2007\end{array}$} & $\begin{array}{l}\text { Yes - LGA } \\
\text { No - EWR, JFK }\end{array}$ & $\begin{array}{c}\text { No } \\
\text { Change }\end{array}$ & $\begin{array}{c}\text { No } \\
\text { Change }\end{array}$ & Worsened \\
\hline & $\begin{array}{l}\text { No - SFO, SJC, } \\
\text { OAK }\end{array}$ & Improved & $\begin{array}{c}\text { No } \\
\text { Change }\end{array}$ & Worsened \\
\hline \multirow{2}{*}{$\begin{array}{l}+70 \% \\
2007-2008\end{array}$} & $\begin{array}{l}\text { Yes - LGA, } \\
\text { EWR, JFK }\end{array}$ & $\begin{array}{c}\text { No } \\
\text { Change }\end{array}$ & Worsened & Improved \\
\hline & $\begin{array}{l}\text { No - SFO, SJC, } \\
\text { OAK }\end{array}$ & $\begin{array}{c}\text { No } \\
\text { Change }\end{array}$ & Worsened & Worsened \\
\hline
\end{tabular}

Table 1. NY \& SF Summary of Analysis

The highlights of the results of this paper are:

- Slot controlled airports yielded improved performance (e.g. average flight delays and cancelled flights) through reductions in frequency and de-peaking schedules without degrading service.

- Non-slot controlled airports yielded degraded increased flight delays and cancellations with no change in markets served or significant changes in airfares.

Even in the presence of fluctuations in passenger demand and economic shocks, passengers saw an improvement in service (i.e. a lessening of delays and cancellation) without any significant loss in markets served or frequency to those markets. The only significant reduction in frequency was to the Washington DC, Boston and Chicago shuttle markets where there was decrease in frequency and an upguaging of aircraft to accommodate the passenger demand. The implications of these results are discussed.

Each of the New York Metroplex Airports restricts the use of runways by way of "slot" controls. The Federal Government allocates a given number of slots in each 30-minute time period to the carriers that service the New York City area. A "slot" provides the holder with the right to announce either a departure or an arrival during this time period. These capacity limits do not restrict schedules that may be impacted by high winds or other weather issues and assumes that there is little variability in these arrivals or departures. Queuing theory dictates that the greater the variability in the arrival and departure patterns, the greater the likelihood for service deterioration. Whenever weather conditions occur (e.g. storms, ice, fog, high winds), the capacity of the airport is further reduced. Bobby Sturgell, Acting Administrator of the FAA, said on November 24, 2008 "Schedules predicated on a bright sunny day everyday are just flat out impractical. These create unrealistic expectations on the part of the passenger, and they create havoc anytime when weather hits." 10

Currently the San Francisco Metroplex does not have slot controls in effect. By doing comparisons of how the airlines in these two regions reacted, in terms of their schedules, to the changes in fuel costs, and slot controls, we hope to better understand the impact that slot regulations might have on airline and passenger behaviors. Additionally, the San Francisco Metroplex has been identified as one of three additional Metropolitan areas needing additional capacity in 2015 after all planned improvements are made. ${ }^{11}$ Thus, we have chosen a Metroplex to compare to the New York Metroplex where there is significant traffic and where weather conditions can significantly impact 
capacity. In addition, both the New York

Metroplex and the San Francisco Metroplex exhibit significant shuttle traffic.

This paper describes an analysis of air transportation system demand, seat capacity, economics, and performance at Metroplex airports during the recent fluctuations in fuel prices. The analysis includes a comparison of the effects of fuel prices at the slot-controlled New York airports and the San Francisco airports.

In this paper, we examine the changes in airline ticket prices, air transportation demand, airline revenues, and flight performance (i.e., delays and cancellations) during a period when there were significant fuel increases, an economic downturn and stricter slot controls at the New York Metroplex but no slot controls at the San Francisco airports.

The organization of this paper is as follows: Section 2 describes the method of analysis. Section 3 describes the results of the analysis for markets, economics, and flight performance. Section 4 describes a statistical analysis of the trends. Section 5 discusses conclusions and future Work.

\section{METHOD OF ANALYSIS}

This study provides a longitudinal study, from 2005 through fall 2008, that describes three major characteristics of the New York and San Francisco Metropolitan Air Transportation Systems: (a) a description of the markets served from each airport including frequency of service, aircraft size used, and competition within the market; (b) an economic analysis of the markets as specified by ticket prices, airline revenue and costs, and variation in ticket price; and (c) how airline schedules impact passengers through an analysis of load factors, delays and cancellations. Figure 1 is an illustration of how fuel prices, seasonal flight patterns and federal regulations impact airline and passenger behavior resulting in changes in market structure, prices, and schedules. These, in turn, determine demands, load factors and delays.

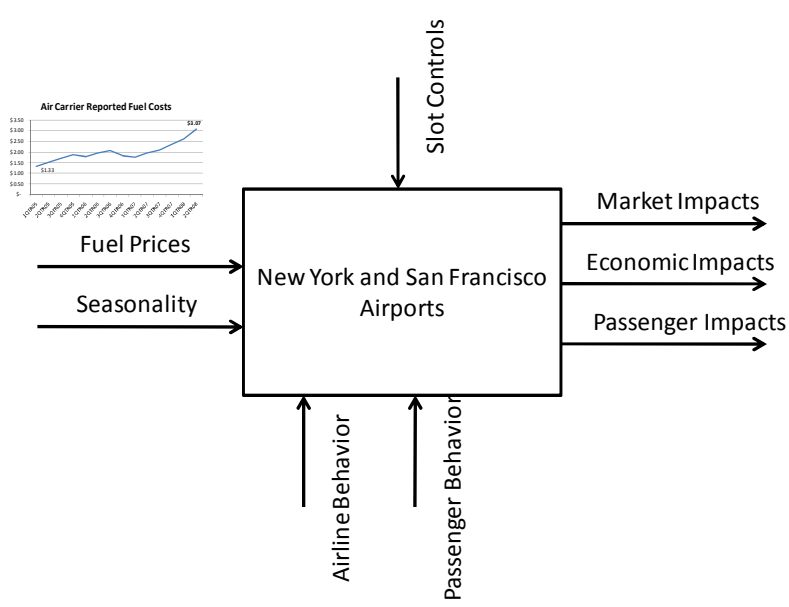

Figure 1. NY \& SF Metroplex fuel price study

This study analyzes changes in system behavior between 2005 and 2007. During this period, the slot control regulations at the New York airports did not change but there was a 57\% increase in fuel prices that impacted both airport Metroplexes. We then examine behavior between 2007 and 2008. During this period, slot controls were tightened and fuel prices continued to increase by another $70 \%$. We will test any changes for statistical significance.

\section{Market Analysis}

We define our metrics next.

Markets Served: Markets served by the NY/NJ Metroplex is defined as any location served from a NY/NJ airport with at least sixty or more arrivals and departures per month, as reported to BTS.

Aircraft size: is the average number of seats per aircraft for various O/D pairs as reported to BTS.

Flights per day: is the number of arrivals per day from other metroplexes as reported to the Bureau of Transportation Statistics (BTS). ${ }^{12}$

\section{Economic Analysis}

In this analysis, we analyze the changes in airline revenues, airline costs, ticket prices and demand over time. Specifically:

Airline Costs: Costs include personnel, fuel, insurance, taxes, maintenance, and depreciation per flight hour and reported to BTS by aircraft 
type. Airline costs as reported here is calculated by multiplying average flight times as reported in the Aviation system performance metrics (ASPM) aircraft cost per flight hour and then multiplying the result by the number of flights per quarter. ${ }^{13}$

Average Airfare: We report the average airfare during a given quarter, as reported in the $10 \%$ price sample provided to BTS. Single segment fares were used for this analysis. This analysis does not completely include the cost of travel by the passenger since it does not reflect any baggage, fuel fees, or other incidentals (e.g. blanket, movie, food) not reported to BTS. Airline Revenue: Airline revenue is calculated by subtracting airline costs from estimated revenues. For each market, the revenue is determined by calculating the average single segment fare for that O/D pair and multiplying this average fare by the total passengers flown in that quarter. This profit analysis does not include any additional fees charged by the airline or any additional costs that the airline might incur due to delays in schedules.

\section{Flight Performance}

Finally, our flight performance analysis reports the following metrics:
Flight Delay: We report the number of delayed flights (flights with delays of 15 minutes or more).

Average Flight Delay: We report the average delay of delayed flights.

Load Factor: Load factor is the ratio of passengers flown to the average seat capacity for each O/D pair studied, as reported to BTS. Flight Cancellations: Flight cancellations count the total number of flights cancelled for each $\mathrm{O} / \mathrm{D}$, as reported to BTS.

\section{RESULTS OF ANALYSIS}

\section{SUMMARY OF ANALYSIS}

The results indicate that slot controlled airports yielded improved performance (e.g. flight delays and cancelled flights) through reductions in frequency and de-peaking schedules without degrading service. Even in the presence of fluctuations in passenger demand and economic shocks, passengers saw an improvement in service (i.e. a lessening of delays and cancellation) without any significant loss in markets served or frequency to those markets. 


\begin{tabular}{|c|c|c|c|c|}
\hline Fuel Prices & Slot Controls & Market & **Economic & Flight Performance \\
\hline \multirow{8}{*}{$\begin{array}{l}+57 \% \\
2005-2007\end{array}$} & \multirow{4}{*}{$\begin{array}{c}\text { Yes - LGA } \\
\text { No- EWR, JFK }\end{array}$} & Markets reduced 3\% & $\begin{array}{l}\text { Operating Cost } \\
\text { increased } 20 \%\end{array}$ & $\begin{array}{l}\text { *Flight Delays } \\
\text { increased } 39 \%\end{array}$ \\
\hline & & $\begin{array}{l}{ }^{*} \text { Aircraft Size } \\
\text { reduced } 3 \%\end{array}$ & $\begin{array}{c}\text { Airfare increased } \\
8 \%\end{array}$ & $\begin{array}{l}\text { *Average Delay } \\
\text { increased } \mathbf{4 8 \%}\end{array}$ \\
\hline & & $\begin{array}{l}\text { *Flights/ Day } \\
\text { increased } 4 \%\end{array}$ & $\begin{array}{c}\text { Revenue increased } \\
22 \%\end{array}$ & $\begin{array}{l}\text { Cancellations } \\
\text { increased } 34 \%\end{array}$ \\
\hline & & & & $\begin{array}{l}\text { *Load Factors } \\
\text { increased 3\% }\end{array}$ \\
\hline & \multirow{4}{*}{$\begin{array}{c}\text { No - SFO, SJC, } \\
\text { OAK }\end{array}$} & $\begin{array}{c}\text { *Markets increased } \\
4 \%\end{array}$ & $\begin{array}{l}\text { Operating Cost } \\
\text { increased } 9 \%\end{array}$ & $\begin{array}{l}\text { *Flight Delays } \\
\text { increased } \mathbf{3 0 \%}\end{array}$ \\
\hline & & $\begin{array}{l}{ }^{*} \text { Aircraft Size } \\
\text { reduced } 1 \%\end{array}$ & $\begin{array}{c}\text { Airfare increased } \\
10 \%\end{array}$ & $\begin{array}{l}\text { *Average Delay } \\
\text { increased } 29 \%\end{array}$ \\
\hline & & $\begin{array}{l}\text { *Flights/ Day } \\
\text { increased } 4 \%\end{array}$ & $\begin{array}{c}\text { Revenue increased } \\
15 \%\end{array}$ & $\begin{array}{l}{ }^{*} \text { Cancellations } \\
\text { increased } \mathbf{4 7 \%}\end{array}$ \\
\hline & & & & $\begin{array}{l}\text { Load Factors remained } \\
\text { the same }\end{array}$ \\
\hline \multirow{8}{*}{$\begin{array}{l}+70 \% \\
2007-2008\end{array}$} & \multirow{4}{*}{$\begin{array}{l}\text { Yes - LGA, } \\
\text { EWR, JFK }\end{array}$} & Markets reduced $2 \%$ & $\begin{array}{l}\text { Operating Cost } \\
\text { increased } 24 \%\end{array}$ & $\begin{array}{l}\text { *Flight Delays } \\
\text { decreased } 18 \%\end{array}$ \\
\hline & & $\begin{array}{l}\text { Aircraft Size } \\
\text { increased 1\% }\end{array}$ & $\begin{array}{c}\text { Airfare increased } \\
7 \%\end{array}$ & $\begin{array}{l}\text { *Average Delay } \\
\text { decreased } 14 \%\end{array}$ \\
\hline & & $\begin{array}{l}\text { *Flights/Day } \\
\text { decreased 6\% }\end{array}$ & $\begin{array}{c}\text { Revenue increased } \\
5 \%\end{array}$ & $\begin{array}{l}{ }^{*} \text { Cancellations } \\
\text { decreased } \mathbf{1 8 \%}\end{array}$ \\
\hline & & & & $\begin{array}{l}\text { *Load Factors } \\
\text { decreased 3\% }\end{array}$ \\
\hline & \multirow{4}{*}{$\begin{array}{c}\text { No - SFO, SJC, } \\
\text { OAK }\end{array}$} & $\begin{array}{l}\text { Markets remained } \\
\text { the same }\end{array}$ & $\begin{array}{l}\text { Operating Cost } \\
\text { increased } 28 \%\end{array}$ & $\begin{array}{l}\text { Flight Delays } \\
\text { decreased } 7 \%\end{array}$ \\
\hline & & $\begin{array}{l}\text { Aircraft Size } \\
\text { remained the same }\end{array}$ & $\begin{array}{c}\text { Airfare increased } \\
2 \%\end{array}$ & $\begin{array}{l}\text { Average Delay } \\
\text { increased 9\% }\end{array}$ \\
\hline & & $\begin{array}{c}\text { *Flights/ Day } \\
\text { decreased 5\% }\end{array}$ & $\begin{array}{c}\text { Revenue increased } \\
3 \%\end{array}$ & $\begin{array}{l}\text { Cancellations } \\
\text { increased } 6 \%\end{array}$ \\
\hline & & & & $\begin{array}{l}\text { *Load Factors } \\
\text { decreased 3\% }\end{array}$ \\
\hline
\end{tabular}

* 95\% Statistically Significant w/ Wilcoxon Sign Rank Test $\quad * *$ Too few data points for statistical tests

Table 2. NY \& SF Analysis Results

\section{MARKET ANALYSIS}

\section{Markets Served}

There was little change to the number of markets served by the New York and San Francisco Metroplex airports since January 2005. Although New York serves over 100 markets, the number of markets served by at least 60 flights per month (i.e. having at least one arrival and departure daily) is approximately 70. Similarly, the number of San Francisco markets served by at least 60 flights per month is approximately 50 .

The number of markets served by one, two or three of the Metroplex airports remains unchanged from 2005 through 2008 for San Francisco, however this is not the case for New York as seen in figure 2. The analysis shows a sharp decrease in markets served by two or more airports in the New 
York Metroplex starting in the spring of 2008, when fuel costs were high.

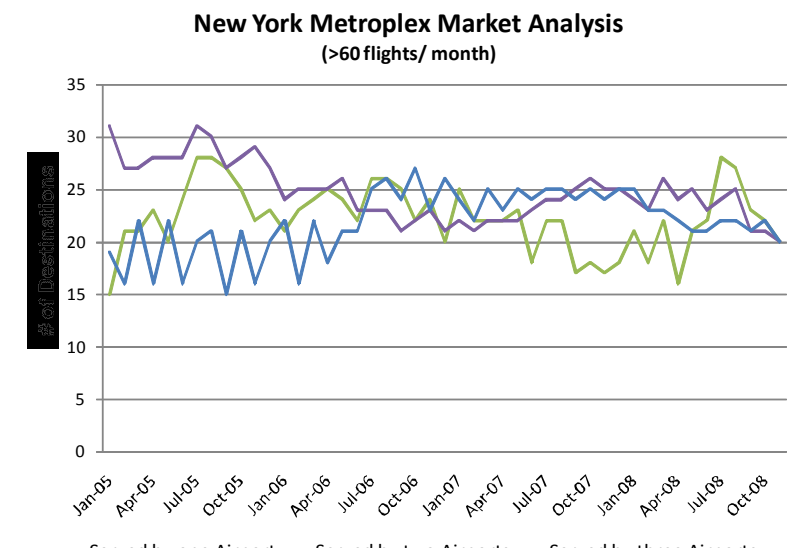

Figure 2. Number of Destinations served with daily service from either one, two or three airports in the NY Metroplex

\section{Aircraft Size}

Two important events occurred in 2008: stricter slot controls were imposed and fuel prices soared. Either of these events might have triggered a reduction in frequency coupled with an upgauging to larger, more efficient aircraft since such actions can improve an airline's profitability. The data does not show any significant overall upgauging in aircraft (See figures 3 and 4). The analysis does indicate that on average, the aircraft size used to service shuttle markets (NY-BOS, NY-WAS, SFLOS, and SF-SAN) has increased, but is still significantly smaller than departures to other metroplexes. A slight down-sizing in seat sizes to other locales has kept the average aircraft size constant over time with little seasonal differences. ${ }^{14}$

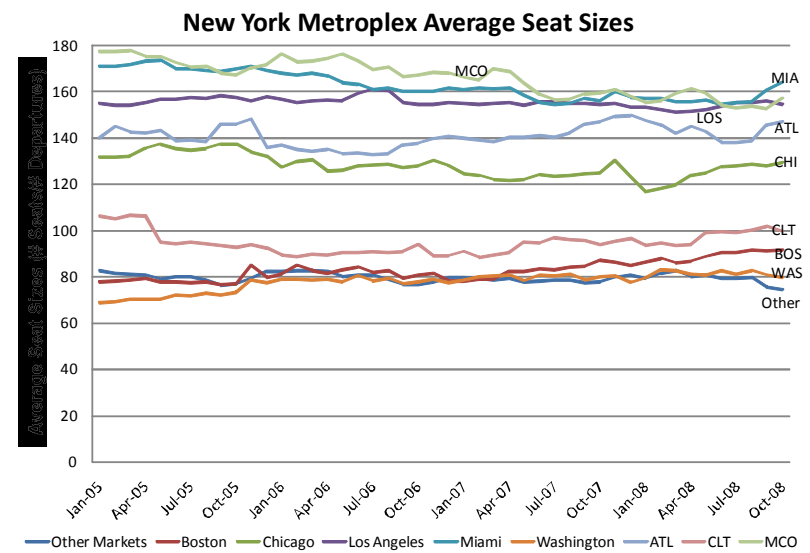

Figure 3. NY Metroplex Average Aircraft Size

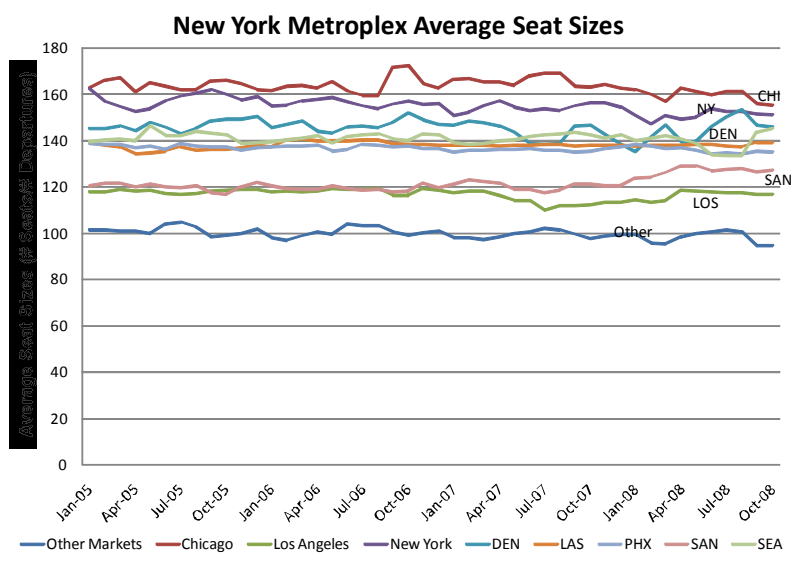

Figure 4. NY Metroplex Average Aircraft Size

\section{Flights per day}

There was a $4 \%$ increase of flights to the New York Metroplex from 2005 to 2007 and a 6\% decrease in flights from 2007 to 2008, bringing the number of flights per day in 2008 to $3 \%$ less than the 2005 levels. There was a 5\% increase of flights to the San Francisco Metroplex from 2005 to 2007 and a 4\% decrease in flights from 2007 to 2008, bringing the number of flights per day in 2008 back to the 2005 levels.

The increase in fuel costs and the downturn in the economy could have influenced the decision of airlines to reduce their schedules in 2008, since we see corresponding reductions in scheduled flights for both the New York and San Francisco airports.

The imposition of slot controls imposed by Department of Transportation (DOT) in 2008 is the most likely cause of the increased reductions in scheduled flights in 2008 for the New York Metroplex, when reviewing schedules; we see that the schedule changes exactly match the regulations set by DOT. With the significant costs of fuel, we may have expected a greater decline in scheduled flights. 


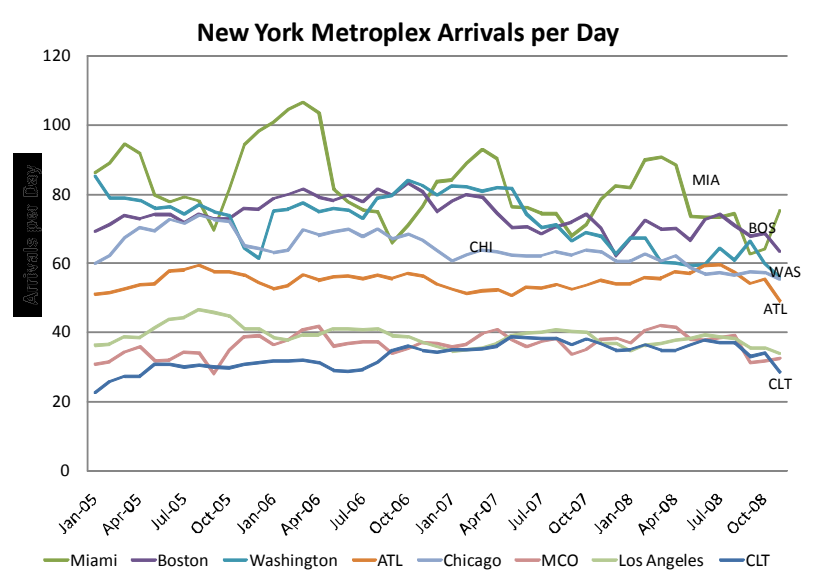

Figure 5. NY Metroplex Arrivals per Day

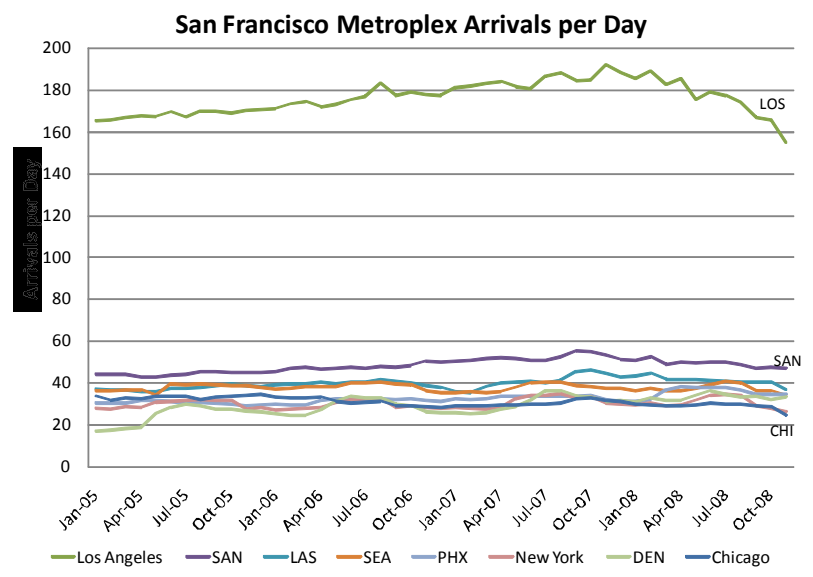

Figure 6. SF Metroplex Arrivals per Day

Although the number of flights per day remained relatively constant, seasonality trends exist for the New York major markets (see figure 5). We see more flights to Miami in the colder months and more flights to overseas locations in the summer. This seasonality was not observed for the San Francisco major markets, see figure 6.

Two other changes in the markets served during this period were: (a) There was a drop of 25 arrivals per day from the Washington D.C. metroplex to EWR, and (b) There has also been a reduction in the number of arrivals per day at EWR and LGA from the Chicago Metroplex.

\section{ECONOMIC ANALYSIS}

To better understand the economic impact of increased fuel prices, slot controls and/or congestion, we examined ticket prices over time at both the New York and the San Francisco airports. This study examines the New York and San Francisco airports as a whole, on shuttle service markets, on major hubs, and on long haul markets. Finally the estimated revenue generated by flights to a variety of locations is also collected and graphed.

\section{Airline Costs}

The airline costs per hour of flight since 1QT 2005 reflect the changes to fuel prices and show no seasonality, see figure 14 . While personnel, training, maintenance, and depreciation costs have remained level, the fuel costs have increased $166 \%$ since first quarter 2005. The air carriers have experienced over $70 \%$ of this increase fuel since the first quarter 2007. Thus, the only significant variability in airline costs over this period is fuel costs.

When applying these cost factors to operations at the New York and San Francisco Metroplexes the analysis shows a $49 \%$ and $39 \%$ increases in costs respectively. The estimated operating cost to operate flights in and out of the New York and San Francisco Metroplexes since 1QT 2005 shows seasonality, see figure 7.

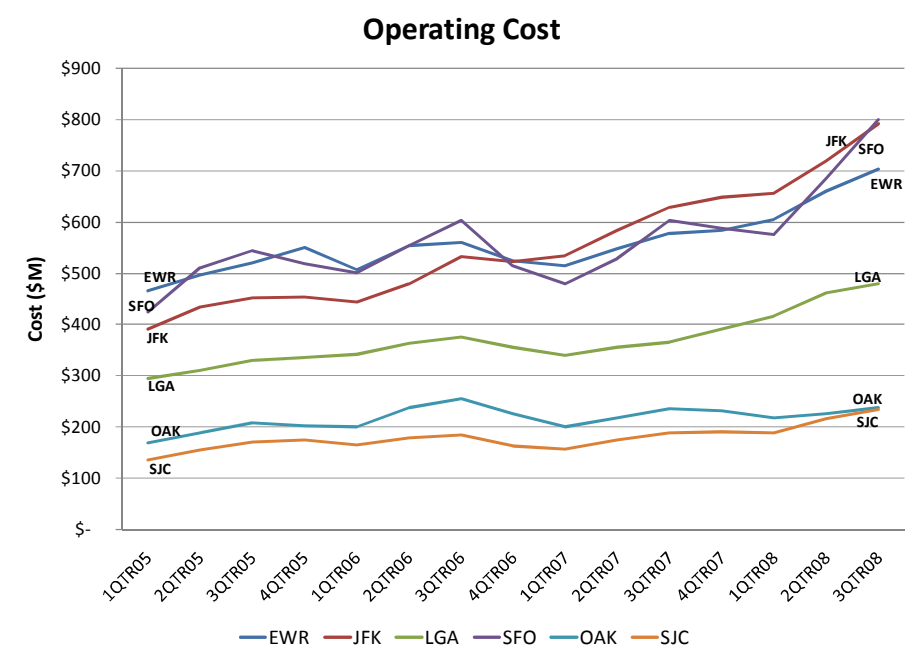

Figure 7. NY \& SF Metroplex Cost 
Airfare

New York and San Francisco Metroplex Average Airfare (2005-2008)

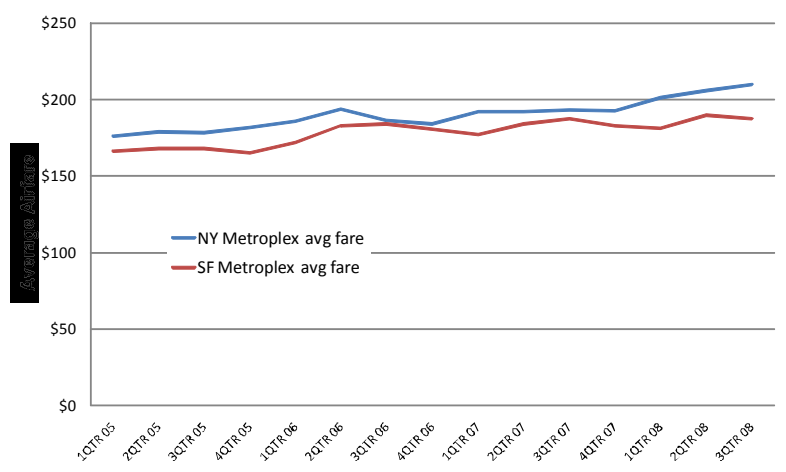

Figure 8. NY \& SF Metroplex Cost

The average airfares paid by passengers since 1QT 2005 reflect the changes to fuel prices and show no seasonality, see figure 8 . This analysis shows the average airfare for the New York and San Francisco Metroplexes increased 15\% and 12\% respectively.

\section{Airline Revenue}

The estimated revenue generated by flights in and out of the New York and San Francisco Metroplexes since 1QT 2005 shows seasonality similar to the trends seen in airline costs, figure 9. Our analysis shows that airlines have compensated for the increased operational costs. Even without the additional revenue generated from new fuel, baggage, food, blanket, movie and other similar fees, the airlines have increased revenue $28 \%$ from 2005 through 2008 in New York and 18\% in San Francisco.

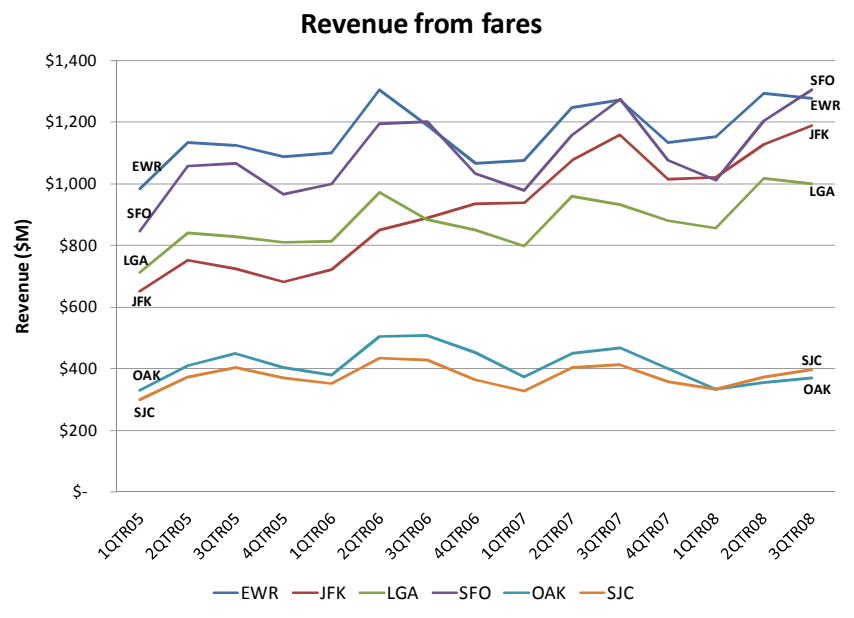

Figure 9. NY \& SF Metroplex Revenue

When evaluating the average annual revenue realized by different sized aircraft serving the New York and San Francisco Metroplexes, we find that the airlines revenue comes primarily from aircraft having between 113-187 seat ranges, see figures 10 and 11 . However in New York 14\% of the revenue is generated from aircraft in the having seats ranging from 38-62.

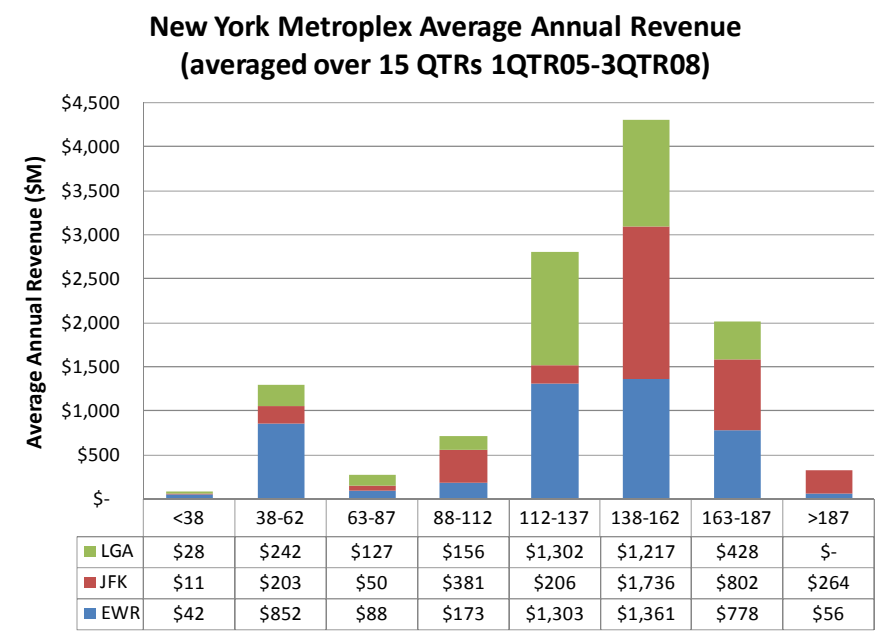

Figure 10. NY Average annual revenue by aircraft size

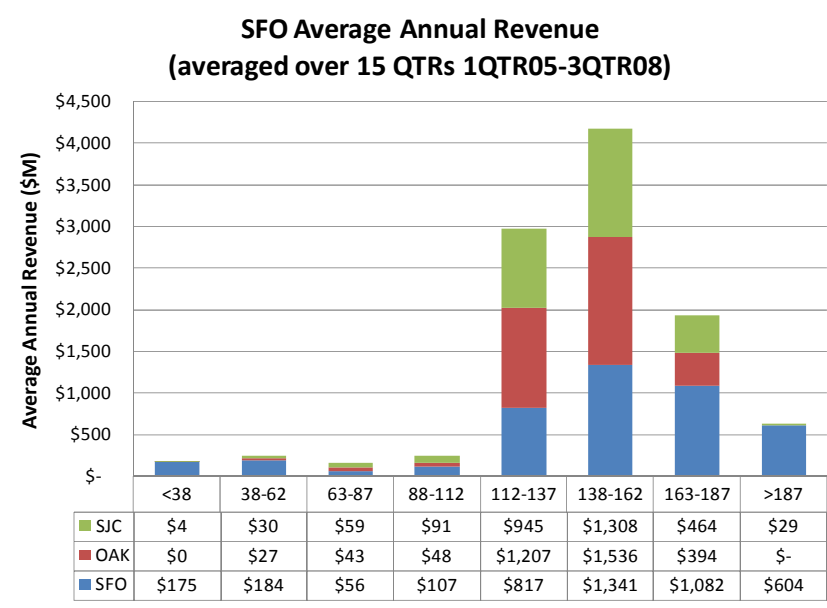

Figure 11. SF Average annual revenue by aircraft size

\section{FLIGHT PERFORMANCE ANALYSIS}

From 2005 to 2007 the reduced aircraft size combined with an increase in arrivals per day increased load factors, delays and cancellations for the New York and San Francisco Metroplexes, see 
Table 3. However, for the New York Metroplex we see a reversal in this trend in 2008, with airlines reducing flights $(-6 \%)$ and increasing aircraft size (1\%). As a result from 2007 to 2008 the New York Metroplex showed significant reductions in the number of Flight Delays (-18\%), average flight delay $(-14 \%)$, the number of flight cancellations ($18 \%)$, and overall passenger delays (-16\%) from both cancellations and delayed flights.

\begin{tabular}{|l|l|l|l|l|l|l|}
\hline Metric & \multicolumn{2}{|l|}{$\begin{array}{l}\text { \% Change } \\
\text { 2005 to 2007 }\end{array}$} & \multicolumn{2}{l|}{$\begin{array}{l}\text { \% Change } \\
\text { 2007 to 2008 }\end{array}$} & \multicolumn{2}{l|}{$\begin{array}{l}\text { \% Change } \\
\mathbf{2 0 0 5} \text { to 2008 }\end{array}$} \\
\hline & NY & SF & NY & SF & NY & SF \\
\hline Fuel Prices & $57 \%$ & $57 \%$ & $70 \%$ & $70 \%$ & $166 \%$ & $166 \%$ \\
\hline Markets & $-3 \%$ & $4 \%$ & $-2 \%$ & $0 \%$ & $-4 \%$ & $4 \%$ \\
\hline Operating Cost & $20 \%$ & $9 \%$ & $24 \%$ & $28 \%$ & $49 \%$ & $39 \%$ \\
\hline Revenue & $22 \%$ & $15 \%$ & $5 \%$ & $3 \%$ & $28 \%$ & $18 \%$ \\
\hline Average Fare & $8 \%$ & $10 \%$ & $7 \%$ & $2 \%$ & $15 \%$ & $12 \%$ \\
\hline Aircraft Size & $-3 \%$ & $-1 \%$ & $1 \%$ & $0 \%$ & $-2 \%$ & $-1 \%$ \\
\hline Arrivals per Day & $4 \%$ & $4 \%$ & $-6 \%$ & $-5 \%$ & $-3 \%$ & $0 \%$ \\
\hline Load Factors & $3 \%$ & $0 \%$ & $-3 \%$ & $-3 \%$ & $1 \%$ & $-3 \%$ \\
\hline \# of Flight Delays & $39 \%$ & $30 \%$ & $-\mathbf{1 8 \%}$ & $-\mathbf{- 7 \%}$ & $\mathbf{1 4 \%}$ & $\mathbf{2 1 \%}$ \\
\hline Average Flight Delay & $48 \%$ & $29 \%$ & $-\mathbf{- 1 4 \%}$ & $\mathbf{9 \%}$ & $\mathbf{2 7 \%}$ & $\mathbf{4 1 \%}$ \\
\hline Flight Cancellations & $34 \%$ & $47 \%$ & $-\mathbf{- 1 8 \%}$ & $\mathbf{6 \%}$ & $\mathbf{1 0 \%}$ & $\mathbf{5 5 \%}$ \\
\hline Passenger Delay & $66 \%$ & $61 \%$ & $\mathbf{- 1 6 \%}$ & $\mathbf{1 \%}$ & $\mathbf{3 9 \%}$ & $\mathbf{6 3 \%}$ \\
\hline
\end{tabular}

\section{Table 3. Longitudinal Change in Metrics}

In contrast, from 2007 to 2008 , the San Francisco Metroplex reduced flights (-3\%) and showed reduced Flight Delays (-7\%), increased average flight delay (9\%), increased flight cancellations (6\%), and increased overall passenger delays (8\%). The fact that DOT imposed slot controls at all three NY Metroplex airports probably contributes to this contrast in system behavior.

Overall from 2005 to 2008 there were significant increases in the number of Flight delays, average flight delay, the number of flight cancellations, and in the delay incurred by the passenger from both cancellations and delayed flights (see Table 3). ${ }^{15}$

\section{STATISTICAL ANALYSIS OF THE TRENDS}

The annual changes, 2005-2007 and 20072008, for the New York and San Francisco Metroplexes shown in table 3 were tested for significance at the $95 \%$ level. Since most of the data, measured as monthly observations, did not pass the Kolmogorov-Smirnov test assumption of normally-distributed data, the Wilcoxon Sign Rank
Test (a non-parametric test) was used to test these trends for significance, see table 4.

\begin{tabular}{|l|l|l|l|l|l|l|}
\hline Metric & \multicolumn{2}{|c|}{$\begin{array}{l}\text { \% Change } \\
\mathbf{2 0 0 5} \text { to 2007 }\end{array}$} & \multicolumn{2}{l|}{$\begin{array}{l}\text { \% Change } \\
\mathbf{2 0 0 7} \text { to 2008 }\end{array}$} & \multicolumn{2}{l|}{$\begin{array}{l}\text { \% Change } \\
\mathbf{2 0 0 5} \text { to 2008 }\end{array}$} \\
\hline $\begin{array}{c}\text { Wilcoxon Sign Rank Test } \\
\text { Significant Trend }\end{array}$ & NY & SF & NY & SF & NY & SF \\
\hline Markets & $-3 \%$ & $4 \%$ & $-2 \%$ & $0 \%$ & $-4 \%$ & $4 \%$ \\
\hline Aircraft Size & $-3 \%$ & $-1 \%$ & $1 \%$ & $0 \%$ & $-2 \%$ & $-1 \%$ \\
\hline Arrivals per Day & $4 \%$ & $4 \%$ & $-6 \%$ & $-5 \%$ & $-3 \%$ & $0 \%$ \\
\hline Load Factors & $3 \%$ & $0 \%$ & $-3 \%$ & $-3 \%$ & $1 \%$ & $-3 \%$ \\
\hline \# of Flight Delays & $39 \%$ & $30 \%$ & $-18 \%$ & $-7 \%$ & $14 \%$ & $21 \%$ \\
\hline Average Flight Delay & $48 \%$ & $29 \%$ & $-14 \%$ & $9 \%$ & $27 \%$ & $41 \%$ \\
\hline Flight Cancellations & $34 \%$ & $47 \%$ & $-18 \%$ & $6 \%$ & $10 \%$ & $55 \%$ \\
\hline Passenger Delay & $66 \%$ & $61 \%$ & $-16 \%$ & $1 \%$ & $39 \%$ & $63 \%$ \\
\hline
\end{tabular}

\section{Table 4. Significance tests for Trends}

The results showed the 2005 to 2007 changes in aircraft size, arrivals per day, flight delays, average flight delay, and passenger delay were significant for both metroplexes, increased load factors were significant for New York, and increased markets served and flight cancellations were significant for San Francisco.

Therefore, we conclude that during a period where both Metroplexes saw an increase in fuel prices but no change in regulations (slots controls were in effect only at LGA), we observe similar airline behavior resulting in worsening flight performance at both Metroplexes.

We see a different result when examing the actions of the airlines in 2008. During this period both Metroplexes had similar increased fuel charges, but new slot control regulations impacted all three New York airports. During this time, the New York airports showed significant reductions in flight delays (14\%) and cancellations (18\%) in New York. In contrast, San Francisco did show increases of flight delays of $9 \%$ and increase in cancellations of $6 \%$, but neither of these changes proved to be statistically significant.

Other differences in behavior between the two Metroplexes was not significant, in terms of arrivals per day or load factors. 


\section{OBSERVATIONS, CONCLUSIONS, and FUTURE WORK}

\section{Observations}

For shuttle markets (LOS, WAS, \& BOS), we see that the same trend toward smaller planes, low load factors and higher cancellation rates. Both metroplexes showed seasonality in their cancelled and delayed flights. In addition, we see that there are significant cancellations from San Francisco to Chicago and Denver. In this case, United Airlines is the major hub carrier in San Francisco and it has hubs at both Denver and Chicago. Thus, United can more easily accommodate cancelled passengers that are connecting at these airports. This shows the same trend as observed for shuttle flights, i.e. high frequency markets are the most likely to experience cancellations since the airlines can better accommodate these passengers onto other flights, since these flights have lower load factors and significant frequency.

The differences in delays and schedule reductions observed in this study between New York and San Francisco Metroplexes may be attributed to the fact that New York had slot controls imposed and tightened during this period, where as San Francisco had no such regulations. Thus, delays were reduced in New York due to a reduction in schedule. Airlines in both regions attempted, where possible, to maintain market share and therefore chose to reduce aircraft size rather than reduce either markets served or frequency.

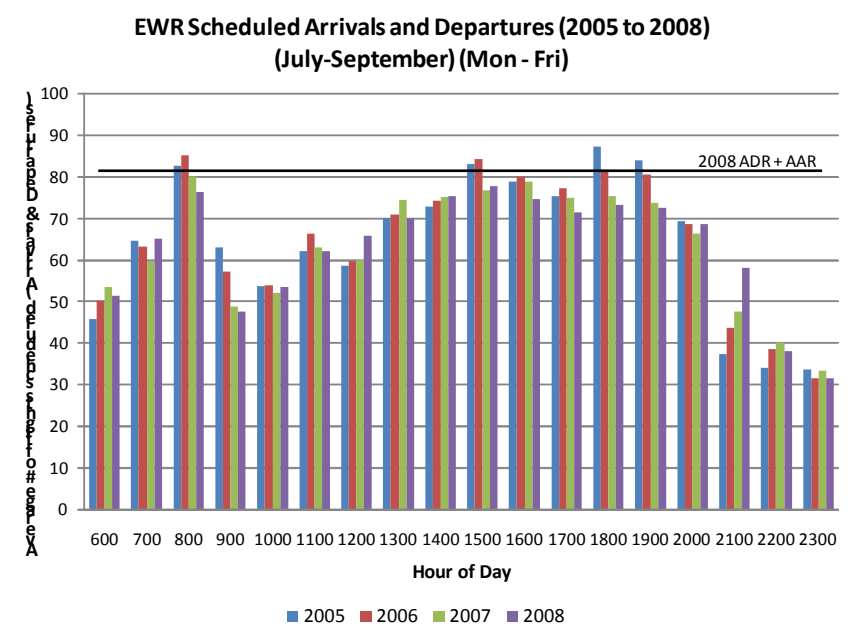

Figure 12. EWR Schedule adjustments 05-08
In 2008, slot controls and increased fuel increases have triggered the New York airlines to redistribute flight schedules (see figures 12 and 13) and reduce flights by $6 \%$, see table 3 . These actions had the effect of reducing the number of Flight Delays (-18\%), average flight delay (-14\%), the number of flight cancellations $(-18 \%)$, and the delay incurred by the passenger (-16\%) from both cancellations and delayed flights, see table 3 .

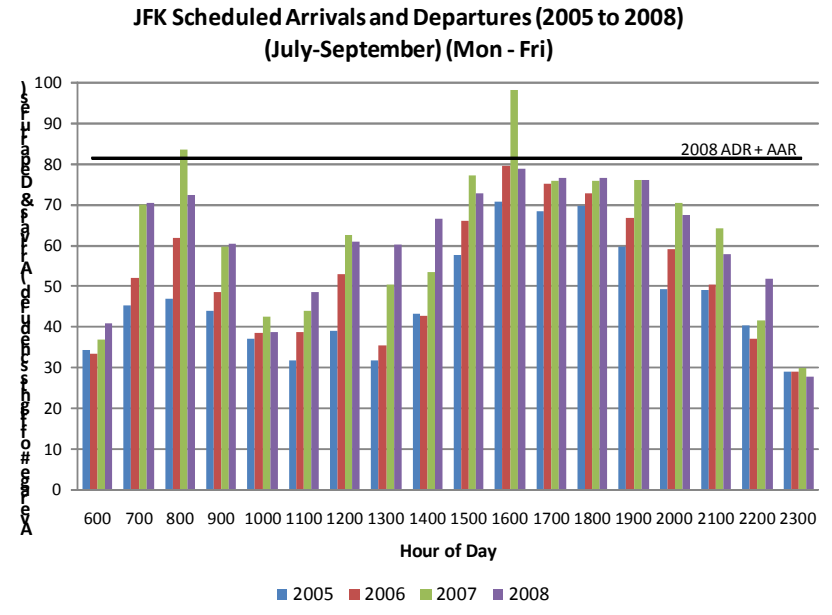

Figure 13. JFK Schedule adjustments 05-08

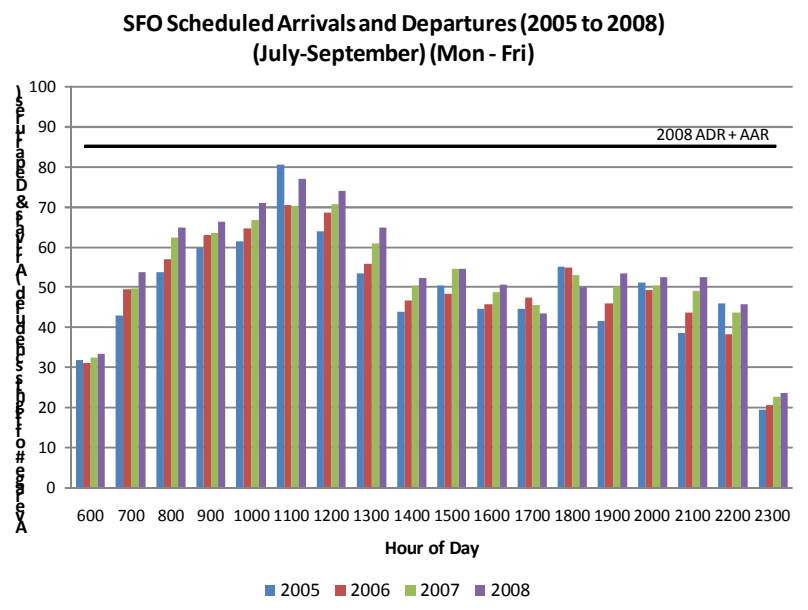

Figure 14. SFO Schedule adjustments 05-08

In 2008 the San Francisco Metroplex had the same increases in fuel prices, but with no slot controls. In this region, airlines redistributed flight schedules (see figure 14) and reduced flights by $5 \%$, see table 3 . However, the average flight delay, the number of flight cancellations and the average passenger delay continued to grow, see table 3. Additionally the revenue for flights in and out of the San Francisco Metroplex was reduced by 3\%, 
while the revenue for flights in and out of the New York Metroplex continued to grow by 5\%, table 3 .

\section{Conclusions}

Our analysis shows no reduction of operations or markets served at the New York Metroplex during this time period, but did show a significant down-gauging of aircraft serving a number of markets (e.g. Dallas to JFK, NY to DC and Boston). One might infer from this analysis, that airlines may choose to continue to serve the same markets, but, when costs increase, they choose to downsize the plane gauge.

Most significantly, in the New York Metroplex, airlines were capable of increasing fares and remaining or increasing profitability during high fuel prices. Airfares to the San Francisco Metroplex were not increased as much and, the resulting change in profitability was not as high. We conjecture that the reduction in flights caused by slot controls allowed the airlines to raise their fares without fear of greater competition, but further study is necessary to confirm this trend. We certainly see a significant change in the duration of delays that occurred once tighter slot controls were imposed. During the same time, delays in San Francisco region increased.

The results indicate that slot controlled airports yielded improved performance (e.g. flight delays and cancelled flights) through reductions in frequency and de-peaking schedules without degrading service or frequency. On the other hand, the non-slot controlled airports in the San Francisco region showed an increase in flight delays and cancellations during the same period. The number of market served and airfares did not change. These results provide some justification for slot-controls at airports that need to manage network congestion. Even in the presence of fluctuations in passenger demand and economic shocks, passengers saw an improvement in service (i.e. a lessening of delays and cancellation) without any significant loss in markets served or frequency to those markets. The only significant reduction in frequency was to the Washington DC, Boston and Chicago shuttle markets where there was decrease in frequency and an upguaging of aircraft to accommodate the passenger demand.

\section{Future Analysis}

Fuel prices dropped in 4QTR 2008, back to the level of those in 2005 . Further study weill allow us to observe how the airlines respond to this change. However, during this period, there has been a significant downturn in the economy. Thus, continual monitoring of ticket prices, schedule changes, aircraft assignment, and load factors over a variety of different economic impulses will help us to better predict future behaviors.

\section{Acknowledgements}

The authors acknowledge the he technical contribution provided by George Donohue, the principle investigator for this research, and Rosa Oseguera-Lohr, our NASA sponsor. This research was sponsored by NASA Award 06 AS2 060014.

The authors acknowledge the he technical contribution provided by Guillermo Calderon-Meza and Juan Wang of the Center for Air Transportation Systems Research at George Mason University.

\section{Email Addresses}

John Ferguson; jfergus3@gmu.edu

Karla Hoffman; khoffman@gmu.edu

Lance Sherry; 1sherry@gmu.edu

Abdul Qadar Kara; akara@gmu.edu

\section{AUTHOR BIOGRAPHY}

Ferguson, John is a Ph.D. student at George Mason University (GMU) and is conducting optimization research on the New York City Metroplex. He has over seventeen years experience as an Operations Research Analyst and as a Systems Engineer for the Department of Defense.

Hoffman, Karla teaches Operations Research at GMU and previously was employed at NIST as a mathematician. Dr. Hoffman's primary areas of research are transportation, auctions, and combinatorial optimization. She has served as a consultant to the FAA, FCC, DOT, DOD, the IRS, and to various telecommunications, transportation, entertainment and military companies. 
Dr. Sherry is Associate Research Professor of System Engineering and Operations Research and is Executive Director of the Center for Air Transportation Systems Research (CASTR) at GMU. Dr. Sherry is a system engineer with over 20 years of practical experience in air transportation operations and the design/flight-test/certification of commercial avionics. Dr. Sherry has served as control engineer, system engineer, lead system engineer, avionics flight test engineer, and program manager, has also served as Principal Investigator on research projects for FAA, NASA, NSF, DOT, DOE, airports, airlines, aircraft manufacturers and avionics vendors and has published over 100 papers and articles. He holds several patents and has won several awards for his work.

Abdul Qadar Kara is a PhD student at GMU working on the management of Congestion at NY metroplex airports. He has completed his Bachelors from Pakistan at Mohammad Ali Jinnah University and Masters from Germany at Max Planck Institute. He has over 6 years experience of programming and problem solving.

\section{REFERENCES}

1 L. Sherry, and G Donohue, "U.S. Airline Passenger Trip Delay Report (2007)," Center for Air Transportation Systems Research Report, George Mason University, pp. 5, 2008 .

${ }^{2}$ S. Lan, J.P. Clarke, and C. Barnhart, "Planning for robust airline operations: optimizing aircraft routings and flight departure times to minimize passenger disruptions," Transportation Science 40, pp. 15-28, 2006.

${ }^{3}$ B. Manley and L. Sherry, "Impact of ground delay program rationing rules on passenger and airline equity," Integrated Communications, Navigation and Surveillance Conference, 2008. ICNS 2008, pp.1-11, 5-7 May 2008.

${ }^{4}$ P. Cox, New York Post, (May 26, 2008).

${ }^{5}$ The MITRE Corporation, "Capacity Needs in the National Airspace System (2007-2025)", FAA Fact 2 Report, pp.9, May 2007

${ }^{6}$ L. T. Le G. Donohue, K. L. Hoffman and C. Chen, "Optimum Airport Capacity Utilization under Congestion Management: A Case Study of New York LaGuardia Airport", Transportation Planning and
Technology -Special Issue: Approaches for Developing the Airports of the Future, 2007

${ }^{7}$ G. Donohue and R. Shaver, "Terminal Chaos", American Institute of Aeronautics and Astronautics, Inc., pp. 55, 2008.

${ }^{8}$ L. Wang ; G. Donohue; K. Hoffman; and L. Sherry, "Analysis of Air Transportation for the New York Metroplex: Summer 2007”, International Conference on Research in Air Transportation (ICRAT 2008).

${ }^{9}$ M.O. Ball, G. Donohue, and K. Hoffman, "Auctions for the safe, efficient and equitable allocation of airspace system resources," Combinatorial Auctions, MIT Press, Cambridge, MA, pp. 507-538, 2005.

${ }^{10}$ P. Cramton, M. O. Ball, L. M. Ausubel, F. Berardino, G. Donohue, M. Hansen, and K. Hoffman. "MarketBased Alternatives for Managing Congestion at New York's LaGuardia Airport" Optimal Use of Scarce Airport Capacity, Proceedings of AirNeth Annual Conference. The Hague: 2007.

${ }^{11}$ The MITRE Corporation, "Capacity Needs in the National Airspace System (2007-2025)”, FAA Fact 2 Report, pp.15, May 2007.

${ }^{12}$ Bureau of transportation statistics (BTS) databases and statistics. Accessed December 2008. http://www.transtats.bts.gov/

${ }^{13}$ Aviation system performance metrics (ASPM)complete, FAA.

${ }^{14}$ W. Wei and M. Hansen, "Airlines' competition in aircraft size and service frequency in duopoly markets", Transportation Research Part E: Logistics and Transportation Review, Volume 43, Issue 4, pp. 409424, July 2007.

${ }^{15}$ Tu, Y., M. O. Ball, and J. Wolfgang, "Estimating Flight Departure Delay Distributions - A Statistical Approach with Long-Term Trend and Short-Term Pattern", Robert H. Smith School Research Paper, RHS 06-034, 2005.

2009 ICNS Conference 13-15 May 2009 